\title{
Relationship between cobalamin deficiency and delirium in elderly patients undergoing cardiac
}

\section{surgery}

\author{
Utkan Sevuk' \\ Erkan Baysal ${ }^{2}$ \\ Nurettin $\mathrm{Ay}^{3}$ \\ Yakup Altas ${ }^{2}$ \\ Rojhat Altindag ${ }^{2}$ \\ Baris Yaylak ${ }^{2}$ \\ Vahhac Alp ${ }^{3}$ \\ Ertan Demirtas ${ }^{4}$ \\ 'Department of Cardiovascular \\ Surgery, Diyarbakir Gazi Yasargil \\ Education and Research Hospital, \\ Diyarbakir, ${ }^{2}$ Department of \\ Cardiology, Diyarbakir Gazi \\ Yasargil Education and Research \\ Hospital, Diyarbakir, ${ }^{3}$ Department \\ of General Surgery, Diyarbakir Gazi \\ Yasargil Education and Research \\ Hospital, Diyarbakir, ${ }^{4}$ Department of \\ Cardiovascular Surgery, Liv Hospital, \\ Ankara, Turkey
}

This article was published in the following Dove Press journal:

Neuropsychiatric Disease and Treatment

7 August 2015

Number of times this article has been viewed

Background: Delirium is common after cardiac surgery and is independently associated with increased morbidity, mortality, prolonged hospital stays, and higher costs. Cobalamin (vitamin $\mathrm{B}_{12}$ ) deficiency is a common cause of neuropsychiatric symptoms and affects up to $40 \%$ of elderly people. The relationship between cobalamin deficiency and the occurrence of delirium after cardiac surgery has not been examined in previous studies. We examined the relationship between cobalamin deficiency and delirium in elderly patients undergoing coronary artery bypass grafting (CABG) surgery.

Material and methods: A total of 100 patients with cobalamin deficiency undergoing CABG were enrolled in this retrospective study. Control group comprised 100 patients without cobalamin deficiency undergoing CABG. Patients aged 65 years or over were included. Diagnosis of delirium was made using Intensive Care Delirium Screening Checklist. Delirium severity was measured using the Delirium Rating Scale-revised-98.

Results: Patients with cobalamin deficiency had a significantly higher incidence of delirium $(42 \%$ vs $26 \% ; P=0.017)$ and higher delirium severity scores $(16.5 \pm 2.9$ vs $15.03 \pm 2.48 ; P=0.034)$ than patients without cobalamin deficiency. Cobalamin levels were significantly lower in patients with delirium than patients without delirium $(P=0.004)$. Delirium severity score showed a moderate correlation with cobalamin levels $(\rho=-0.27 ; P=0.024)$. Logistic regression analysis demonstrated that cobalamin deficiency was independently associated with postoperative delirium (OR 1.93, 95\% CI 1.03-3.6, $P=0.038$ ).

Conclusion: The results of our study suggest that cobalamin deficiency may be associated with increased risk of delirium in patients undergoing CABG. In addition, we found that preoperative cobalamin levels were associated with the severity of delirium. This report highlights the importance of investigation for cobalamin deficiency in patients undergoing cardiac surgery, especially in the elderly.

Keywords: cobalamin deficiency, coronary artery bypass grafting, delirium, delirium severity score, elderly

\section{Background}

Delirium is an acute confusional state characterized by disturbance of consciousness with inattention accompanied by a change in cognition or perceptual disturbance that develops over a short period of time (hours to days) and fluctuates over time. ${ }^{1}$ Delirium is common in patients undergoing cardiac surgery. Its incidence after cardiac surgery has been reported as $8 \%-52 \%$ and is independently associated with increased morbidity, mortality, prolonged hospital stays, and higher costs. ${ }^{2,3}$ Therefore, recognizing the factors associated with delirium is crucial to prevent and decrease the negative consequences related to delirium.
Correspondence: Utkan Sevuk Diyarbakir Gazi Yașargil Egitim ve Arastirma Hastanesi, Kalp ve Damar Cerrahisi Klinigi, 3 kat, Uckuyular, Diyarbakir 21010, Turkey

Tel +905055307095

Email utkansevuk@gmail.com 
Delirium usually has a multifactorial etiology. Previous studies have shown that advanced age, preoperative cognitive impairment, depression, benzodiazepine use, cerebrovascular and peripheral vascular disease, preoperative cerebral oxygen saturation, smoking, atrial fibrillation, renal dysfunction, heart failure, low intraoperative perfusion pressure and cardiogenic shock are associated with increased risk of postoperative delirium. ${ }^{4,5}$

Cobalamin (vitamin $\mathrm{B}_{12}$ ) deficiency is characterized by hematologic, psychiatric, and neurologic disturbances and affects up to $40 \%$ of elderly people. ${ }^{6}$ The reported prevalence of deficient and marginal values is much higher in developing countries. ${ }^{7}$ Cobalamin deficiency is a common cause of neuropsychiatric symptoms and has been linked to psychiatric disorders such as depression, dementia, catatonia, delirium, schizophrenia, and psychosis. ${ }^{8-10}$ Even occult cobalamin deficiency has been associated with neuropsychiatric disorders. ${ }^{11}$ Neuropsychiatric symptoms usually precede hematologic signs and are often the presenting manifestation of vitamin cobalamin deficiency. ${ }^{11}$ Mental or psychological changes may precede hematological signs by months or years. ${ }^{11,12}$

The relationship between cobalamin deficiency and the occurrence of delirium after cardiac surgery has not been examined in previous studies. The aim of this study was to examine the relationship between cobalamin deficiency and postoperative delirium in elderly patients undergoing coronary artery bypass grafting (CABG) surgery.

\section{Material and methods Study population}

The present study was approved by the Diyarbakir Gazi Yasargil Education and Research Hospital ethics committee (Diyarbakir, Turkey) and complies with the requirements of the Declaration of Helsinki. We retrospectively reviewed the clinical records of patients who underwent $\mathrm{CABG}$ with cardiopulmonary bypass (CPB) in our hospital between January 2011 and November 2014 for coronary artery disease. Inclusion criteria were as follows: 1) cobalamin deficiency; 2) measurement of serum B12 levels performed within one month prior to the surgery; 3) age $\geq 65$ years; 4) elective, first time $\mathrm{CABG}$ with $\mathrm{CPB}$; 5) intensive care unit (ICU) length of stay $<24$ hours.

The exclusion criteria were as follows: 1) known psychiatric and/or neurologic diseases before surgery; 2) alcohol dependence; 3) chronic kidney and hepatic diseases; 4) chronic heart failure; 5) reduced myocardial function (ejection fraction $<45 \%$ ); 6) severe systemic illness; 7) malignant tumors; 8) acute or chronic infections; 9) carotid artery stenosis; 10) folate deficiency; 11) visual and hearing impairment;
12) emergency procedures; 13) redo-CABG; 14) off-pump $\mathrm{CABG} ; 15)$ preoperative myocardial infarction (MI) within a week; 16) ICU length of stay $>24$ hours; 17) bleeding recorded 12 hours after operation $>1,000 \mathrm{cc}$; 18) postoperative MI; 19) perioperative hemodynamic instability; 20) presence of aortic plaque; and 21) perioperative hypoxia and hypercapnia.

Between January 2011 and November 2014, 437 patients underwent $\mathrm{CABG}$ in our clinic. A total of 159 patients met inclusion criteria. Of the 159 patients, seven were excluded due to incomplete data, three due to known neurologic disease, one due to alcohol dependence, two due to chronic kidney disease, one due to hepatic disease, four due to chronic heart failure and reduced myocardial function (ejection fraction $<45 \%$ ), one due to severe systemic illness, one due to malignant tumor, two due to infections, five due to carotid artery stenosis, five due to folate deficiency, one due to visual and hearing impairment, two due to emergency procedures, one due to redo-CABG, two due to off-pump CABG, two due to preoperative MI within a week, five due to ICU length of stay $>24$ hours, five due to bleeding $>1,000 \mathrm{cc}$ recorded 12 hours after operation, one due to postoperative MI, four due to perioperative hemodynamic instability, one due to presence of aortic plaque, and three due to perioperative hypoxia and hypercapnia.

After applying inclusion and exclusion criteria, 100 patients with cobalamin deficiency were included in the study. Control group comprised 100 patients without cobalamin deficiency. Diagnosis of vitamin $\mathrm{B}_{12}$ deficiency was based on low serum vitamin $B_{12}$ levels $(<191 \mathrm{ng} / \mathrm{L})$, along with megaloblastic anemia. The lowest hematocrit value on bypass was defined as the nadir hematocrit value throughout the CPB. Type 2 diabetes mellitus (DM) was defined as having a fasting plasma glucose levels $\geq 126 \mathrm{mg} / \mathrm{dL}$ or treatment with insulin or an hypoglycemic agent. Hypertension (HT) was defined as systolic blood pressure $>140 \mathrm{mmHg}$, diastolic blood pressure $>90 \mathrm{mmHg}$, or use of an antihypertensive medication. Hyperlipidemia (HL) was defined as total serum cholesterol (TC) $\geq 200 \mathrm{mg} / \mathrm{dL}$ and/or low-density lipoprotein (LDL) cholesterol $\geq 130 \mathrm{mg} / \mathrm{dL}$ and/or triglycerides (TG) $\geq 200 \mathrm{mg} / \mathrm{dL}$ and/or history of current use of lipid-lowering regiment.

\section{Anesthesia}

The following premedication was administered: $10 \mathrm{mg}$ diazepam, per os, was given to all patients on the night prior to operation, and $0.1 \mathrm{mg} / \mathrm{kg}$ morphine $\mathrm{HCl}$ was administered intramuscularly half an hour before the operation. Anesthesia was induced with intravenous fentanyl $5-10 \mu \mathrm{g} / \mathrm{kg}$, midazolam $0.1 \mathrm{mg} / \mathrm{kg}$, rocuronium bromide $0.6-0.8 \mathrm{mg} / \mathrm{kg}$ 
and was maintained with fentanyl 1-2 $\mu \mathrm{g} / \mathrm{kg} / \mathrm{hour}$, rocuronium bromide $0.3 \mathrm{mg} / \mathrm{kg} / \mathrm{hour}$, supported with inhalation of $1 \%-2 \%$ sevoflurane.

\section{Management of CPB}

All procedures were performed with median sternotomy. Standard nonpulsatile CPB with a roller pump and a membrane oxygenator was used. The extracorporeal system was primed with ringer lactate. CPB was established between the ascending aorta and right atrium using dual-stage venous cannula. Prior to the cannulation, 300-400 U/kg heparin sulfate was administered to every patient in order to maintain ACT values above 480 seconds. During CPB, nonpulsatile pumpflow was kept at $2.2-2.5 \mathrm{~L} / \mathrm{m}^{2} /$ minute. Mean arterial pressure during $\mathrm{CPB}$ was stabilized between 50 and $70 \mathrm{mmHg}$. Cold blood cardioplegia was used in all patients. Core temperature was cooled to $28^{\circ} \mathrm{C}$. Alpha-stat strategy was used for $\mathrm{pH}$ management, and all patients were kept at normocapnic levels $\left(\mathrm{PaCO}_{2}=35-45 \mathrm{mmHg}\right)$. Concentrated erythrocyte suspensions were added to pump prime volume, if required to keep the hematocrit level above $20 \%$ during CPB. Proximal anastomoses were completed using a partial occlusion clamp. Postoperative analgesia was achieved by administration of paracetamol or tramadol.

\section{Delirium assessment}

Diagnosis of delirium was made using Intensive Care Delirium Screening Checklist (ICDSC). ${ }^{13}$ The evaluation is based on eight fields (one point each): altered level of consciousness, inattention, disorientation, hallucinationdelusion-psychosis, inappropriate speech or mood, psychomotor agitation/retardation, sleep-wake cycle disturbance, and fluctuating course of aforementioned items. Patients were considered to have delirium if the ICDSC score was equal to or greater than four.

Delirium severity was measured using the Delirium Rating Scale-revised-98 (DRS-R-98). ${ }^{14}$ The DRS-R-98 is a 16-item, clinician-rated scale, with anchored item descriptions corresponding to both symptoms and temporal aspects of delirium. The severity scale has 13 items, each rated from 0 to 3 , with a maximum score of 39 points, and where higher scores indicate greater severity of delirium. Three additional items (rated from 0 to either 2 or 3 ) capture temporal course and attribution to an underlying etiology, and, when added to the sum of the 13 symptom-items, produce the DRS-R-98 total score, which ranges from 0 to 46 . The original validation study suggested cutoff scores for differential diagnosis of around 17-18 points on the total scale and around 15 for the severity scale. However, milder forms of delirium can occur with scores $\geq 11$. $^{14}$

In our ICU, patients are assessed for delirium by using the Turkish versions of ICDSC and DRS R-98 as a standard of care. In recent studies both ICDSC and DRS-R98 were found to be a valid and reliable tool in determining delirium in Turkish population. ${ }^{15,16}$

Neuropsychological assessment by DRS R-98 and ICDSC criteria for delirium was made by experienced bedside nurses twice per day, in the morning and in the afternoon, until discharge from the hospital.

\section{Data collection and laboratory tests}

Demographic, clinical, and laboratory parameters were collected from the patients' charts. All blood samples were collected before CABG. Serum cobalamin levels were determined by chemiluminescent enzyme immunoassay in an automated analyzer (Roche Diagnostic Modular Analytics E170, Roche Ltd., Basel, Switzerland). The normal range for cobalamin in our laboratory is $191-663 \mathrm{ng} / \mathrm{L}$.

\section{Statistical analysis}

Statistical analysis was conducted using SPSS for Windows version 17 (SPSS Inc Chicago, IL, USA). All variables were investigated using visual (histograms, probability plots) and analytic methods (Kolmogorov-Smirnov test) to determine whether or not they are normally distributed. Continuous variables were reported as means and standard deviation for normally distributed variables, and as medians and interquartile range (IQR) for the non-normally distributed variables. Categorical variables were presented using numbers and percentages.

Patients were divided into two subgroups according to the presence or absence of cobalamin deficiency. Comparison between two groups was performed using the chi-square test for qualitative variables, independent $t$-test for normally distributed continuous variables and Mann-Whitney $U$-test for non-normally distributed continuous variables. Patients were further categorized into two subgroups according to the presence or absence of delirium. A similar analysis to that above was made for delirium groups. The strength of linear relations between DRS and clinical variables was assessed by the Pearson or Spearman correlation coefficient as appropriate. Logistic regression analysis was used to evaluate the associations between delirium and cobalamin deficiency. Presence of delirium was used as the dependent variable. Potential risk factors for delirium, and potential predictor variables that had a $P$-value $<0.25$ in the univariate analysis were identified and included as covariates in the multivariate model. The multivariate model was adjusted 
for the following variables: age, sex, DM, COPD, CPB time, and number of transfusions. $P$-values $<0.05$ were considered to indicate statistical significance.

\section{Results}

\section{Relationship between cobalamin deficiency and delirium}

Clinical and biochemical characteristics of the patients with cobalamin deficiency ( $\mathrm{n}=100 ; 66$ males; mean age $70.4 \pm 3.8$ ) and patients without cobalamin deficiency ( $n=100 ; 62$ males; mean age 70.9 \pm 4.1 ) are presented in Table 1.

Patients with cobalamin deficiency had a significantly higher incidence of delirium than those without cobalamin deficiency (42\% vs $26 \% ; P=0.017$ ). In addition, patients with cobalamin deficiency had significantly higher delirium severity scores than patients without cobalamin deficiency $(16.5 \pm 2.9$ vs $15.03 \pm 2.48$; $P=0.034)$. There were no statistically significant differences in other clinical characteristics between the two groups.

\section{Relationship between delirium and clinical variables}

Clinical and biochemical characteristics of the patients with delirium ( $n=68 ; 41$ males; mean age 69.9 44.4$)$ and patients without delirium ( $\mathrm{n}=132 ; 87$ males; mean age $71 \pm 3.66)$ are presented in Table 2. Cobalamin levels were significantly lower in patients with delirium than patients without delirium $(P=0.004)$. There were no statistically significant differences in other clinical characteristics between the two groups.

\section{Multivariate analysis}

The correlation between delirium rating score and evaluated parameters is presented in Table 3. Delirium score showed a moderate correlation with cobalamin levels $(\rho=-0.27$; $P=0.024)$. After adjusting for age, sex, DM, COPD, CPB time, and number of transfusions, logistic regression analysis revealed that cobalamin deficiency was independently associated with postoperative delirium (OR 1.93, 95\% CI 1.03-3.6, $P=0.038$ ).

\section{Discussion}

In the present study, we found that, cobalamin deficiency was associated with increased risk of postoperative delirium and higher delirium severity scores in patients undergoing cardiac surgery. Moreover, preoperative cobalamin levels were significantly lower in patients with delirium compared to patients without delirium. As far as we know, this is the first report of

Table I Differences in clinical and biochemical characteristics of the patients, according to presence or absence of cobalamin deficiency

\begin{tabular}{|c|c|c|c|}
\hline & $\begin{array}{l}\text { Patients with Cbl } \\
\text { deficiency }(n=100)\end{array}$ & $\begin{array}{l}\text { Patients without Cbl } \\
\text { deficiency }(n=100)\end{array}$ & $P$-value \\
\hline Age, years, mean \pm SD & $70.4 \pm 3.8$ & $70.9 \pm 4.1$ & 0.35 \\
\hline Sex, males, $\mathrm{n}$ & 66 & 62 & 0.33 \\
\hline $\mathrm{HT}, \mathrm{n}$ & 83 & 76 & 0.22 \\
\hline DM, $n$ & 29 & 41 & 0.07 \\
\hline HL, n & 57 & 64 & 0.31 \\
\hline Smoking, $\mathrm{n}$ & 63 & 58 & 0.47 \\
\hline PVD, $\mathrm{n}$ & 4 & 9 & 0.15 \\
\hline COPD, n & 28 & 41 & 0.053 \\
\hline EUROSCORE II, mean \pm SD & $0.98 \pm 0.26$ & $1.06 \pm 0.3$ & 0.07 \\
\hline Preoperative HCT & $34.16 \pm 2.8$ & $34.2 \pm 2.6$ & 0.32 \\
\hline Anastomoses, median (IQR) & $4(3-4)$ & $3(2.25-4)$ & 0.36 \\
\hline CPB time, median (IQR) & $103.5(80.25-103.75)$ & $100(85.25-126.75)$ & 0.93 \\
\hline X clamp time, median (IQR) & $65(5 \mathrm{I}-79.5)$ & $60.5(48.25-75)$ & 0.26 \\
\hline Nadir HCT on CPB, median (IQR) & $20(|7|-24)$. & $20.2(18-22.75)$ & 0.9 \\
\hline Operation time, mean $\pm S D$ & $204.7 \pm 29.6$ & $206 \pm 31.07$ & 0.75 \\
\hline Ventilator time, mean \pm SD & $8.3 \pm 2.4$ & $8.5 \pm 2.5$ & 0.85 \\
\hline $\mathrm{RBC}$ transfusion, mean $\pm \mathrm{SD}$ & $2.2 \pm 1.3$ & $2.25 \pm 0.98$ & 0.91 \\
\hline FFP transfusion, mean \pm SD & $0.74 \pm 0.7$ & $0.74 \pm 0.5$ & 0.72 \\
\hline Bleeding recorded 12 hours after operation, median (IQR) & $350(250-450)$ & $300(200-500)$ & 0.55 \\
\hline Delirium, $\mathrm{n}$ & 42 & 26 & $0.017^{*}$ \\
\hline DRS-R-98 severity score, mean \pm SD & $16.5 \pm 2.9$ & $15.03 \pm 2.48$ & $0.034^{*}$ \\
\hline Preoperative Cbl levels, ng/L, median (IQR) & $160(134.2-176)$ & $352(286.5-459)$ & $<0.001 *$ \\
\hline
\end{tabular}

Notes: $* P$-values $<0.05$ were considered to indicate statistical significance.

Abbreviations: Cbl, cobalamin deficiency; HT, hypertension; DM, diabetes mellitus; HL, hyperlipidemia; PVD, peripheral vascular disease; COPD, chronic obstructive pulmonary disease; CPB, cardiopulmonary bypass; X clamp, cross clamp; HCT, hematocrit value; RBC, red blood cell; FFP, fresh frozen plasma; DRS-R-98, Delirium Rating Scale-Revised-98; SD, standard deviation; IQR, interquartile range. 
Table 2 Differences in clinical and biochemical characteristics of the patients, according to presence or absence of delirium

\begin{tabular}{|c|c|c|c|}
\hline & $\begin{array}{l}\text { Patients without delirium } \\
(n=132)\end{array}$ & $\begin{array}{l}\text { Patients with delirium } \\
(n=68)\end{array}$ & $P$-value \\
\hline Age, years, mean $\pm S D$ & $7 I \pm 3.66$ & $69.9 \pm 4.4$ & 0.052 \\
\hline Sex, males, $\mathrm{n}$ & $87(65.9)$ & $4 I(60.3)$ & 0.43 \\
\hline $\mathrm{HT}, \mathrm{n}$ & $106(80.3)$ & $53(77.9)$ & 0.69 \\
\hline $\mathrm{DM}, \mathrm{n}$ & $45(34.1)$ & $25(36.8)$ & 0.7 \\
\hline HL, n & $76(57.6)$ & $45(66.2)$ & 0.23 \\
\hline Smoking, $\mathrm{n}$ & $83(62.9)$ & $38(55.9)$ & 0.33 \\
\hline PVD, $\mathrm{n}$ & $9(6.8)$ & $4(5.9)$ & 0.8 \\
\hline COPD, n & $51(38.6)$ & $18(26.5)$ & 0.08 \\
\hline EUROSCORE II, mean \pm SD & $1.02 \pm 0.27$ & $1.03 \pm 0.31$ & 0.9 \\
\hline Preoperative HCT & $34.14 \pm 2.7$ & $34.3 \pm 2.8$ & 0.22 \\
\hline Anastomoses, median (IQR) & $3(3-4)$ & $4(3-4)$ & 0.75 \\
\hline CPB time, median (IQR) & $101.5(82-124)$ & $107(77.2-125)$ & 0.97 \\
\hline X clamp time, median (IQR) & $62(5 I-78)$ & $65(47.2-77.2)$ & 0.78 \\
\hline Nadir HCT on CPB, median (IQR) & $20(18-23)$ & $21(18-24)$ & 0.09 \\
\hline Operation time, mean $\pm S D$ & $204.7 \pm 30.1$ & $206.8 \pm 30.7$ & 0.64 \\
\hline Ventilator time, mean \pm SD & $8.3 \pm 2.5$ & $8.66 \pm 2.4$ & 0.29 \\
\hline $\mathrm{RBC}$ transfusions, mean $\pm \mathrm{SD}$ & $2.3 \pm 1.1$ & $2.04 \pm 1.22$ & 0.13 \\
\hline FFP transfusion, mean \pm SD & $0.77 \pm 0.6$ & $0.68 \pm 0.67$ & 0.3 \\
\hline Bleeding recorded 12 hours after operation & $350(250-500)$ & $300(200-400)$ & 0.08 \\
\hline Cbl deficiency, $\mathrm{n}$ & $58(43.9)$ & $42(61.8)$ & $0.017 *$ \\
\hline Preoperative Cbl levels, ng/L, median (IQR) & $254(165-388)$ & $184.5(142.5-288.2)$ & $0.004^{*}$ \\
\hline
\end{tabular}

Notes: $* P$-values $<0.05$ were considered to indicate statistical significance.

Abbreviations: $\mathrm{HT}$, hypertension; $\mathrm{DM}$, diabetes mellitus; $\mathrm{HL}$, hyperlipidemia; $\mathrm{PVD}$, peripheral vascular disease; $\mathrm{COPD}$, chronic obstructive pulmonary disease; $\mathrm{CPB}$, cardiopulmonary bypass; X clamp, cross clamp; HCT, hematocrit value; RBC, red blood cell; FFP, fresh frozen plasma; Cbl, cobalamin; SD, standard deviation; IQR, interquartile range.

an association between cobalamin deficiency and postoperative delirium in elderly patients undergoing CABG surgery.

The underlying cause of delirium is often multifactorial, and the pathogenesis of delirium is not entirely understood. Alterations in the levels of neurotransmitters and the neurotransmitter imbalances between the monoaminergic (dopamine, serotonin, norepinephrine) and cholinergic neurotransmitter systems have been proposed to be a leading

Table 3 Correlation between the delirium severity score and clinical variables

\begin{tabular}{llll}
\hline & $\rho$ & $\boldsymbol{r}$ & $\boldsymbol{P}$ \\
\hline Age & - & -0.04 & 0.7 \\
EUROSCORE II & - & 0.23 & 0.06 \\
Cbl level & -0.27 & - & $0.024^{*}$ \\
Number of anastomosis & -0.19 & - & 0.11 \\
CPB time & -0.05 & - & 0.69 \\
X clamp time & -0.09 & - & 0.44 \\
Nadir HCT on CPB & -0.1 & - & 0.4 \\
Operation time & - & -0.13 & 0.29 \\
Ventilator time & - & 0.18 & 0.13 \\
RBC transfusion & - & 0.07 & 0.57 \\
FFP transfusion & - & 0.13 & 0.27 \\
Bleeding recorded I2 hours after & -0.004 & - & 0.94 \\
operation & & & \\
\hline
\end{tabular}

Notes: $* P$-values $<0.05$ were considered to indicate statistical significance.

Abbreviations: $\mathrm{Cb}$, cobalamin; $\mathrm{CPB}$, cardiopulmonary bypass; $\mathrm{X}$ clamp, cross clamp; HCT, hematocrit; RBC, red blood cell; FFP, fresh frozen plasma. pathobiological mechanism for delirium. ${ }^{17}, 18$ Monoamine neurotransmitter system, including the neurotransmitters dopamine, serotonin, and norepinephrin, has a balancing role for the cholinergic activity. Thus, the development of delirium involves interaction between these two neurotransmitter systems, and any process interfering with neurotransmitter function or with the supply or use of substrates can cause delirium. ${ }^{17}$ Other possible mechanisms are neural injury, inflammation, and stress response. ${ }^{17}$ Variable degrees of neurologic injury, ranging from relatively minor neurocognitive deficits to more severe cerebral infarction may occur following cardiac surgery. ${ }^{19}$ Cerebral hypoxia and hypoperfusion and embolization have been implicated in CPB-related cerebral injury. ${ }^{19}$ Inflammation and increase in TNF- $\alpha$, interleukin-10, and soluble TNF-receptor I levels after CPB were also demonstrated to be associated with brain injury in patients undergoing cardiac surgery. ${ }^{20}$

Although the exactmechanism of how vitamin $\mathrm{B}_{12}$ deficiency causes neuropsychiatric disorder is unclear, several mechanisms detailed can contribute to delirium in cobalamin-deficient patients undergoing CABG: 1) impaired monoamine neurotransmitter metabolism, 2) derangements in DNA synthesis, 3) vasculotoxic effects associated with elevated Hcy and demyelination associated with elevated methylmalonic acid levels, 4) diminished protection against inflammatory oxidative stress 
in the perioperative period, and 5) mild cognitive impairment (MCI) and resultant increase in plasma IL-2 and cortisol levels. Cobalamin is critical to central nerve system functioning and is required for the proper biosynthesis of the monoamine neurotransmitters serotonin, epinephrine, and dopamine. ${ }^{21}$ Thus, cobalamin deficiency can lead to decreased production of monoamine neurotransmitters. ${ }^{21}$ A potential mechanism for delirium in patients with cobalamin deficiency may be neurotransmitter imbalances between monoaminergic and cholinergic neurotransmission. Cobalamin deficiency leads to elevated homocysteine and methylmalonic acid levels. ${ }^{21}$ Methylmalonic acid is a myelin destabiliser and can affect normal myelin formation. ${ }^{22}$ Homocysteine has been shown to be neurotoxic, leading to DNA damage and apoptosis..$^{23}$ Previous studies suggested that elevated homocysteine may induce oxidative stress through activation of glutamate receptors and consequent reactive species generation, or by autoxidation to homocysteine and other disulfides releasing $\mathrm{O}_{2}$ and $\mathrm{H}_{2} \mathrm{O}_{2} \cdot{ }^{24,25}$ These findings suggest that, neurotoxicity of homocysteine and methylmalonic acid, which is further augmented by CPB, may provide another mechanism for delirium in patients with cobalamin deficiency. Recent observations suggest that cobalamins exhibit a marked antioxidant activity and provide significant cellular protection against oxidative stress, including those of the inflammatory response. ${ }^{26}$ Cobalamin modulates the immune response and influences cytokine and growth factor production. ${ }^{27}$ Thus, it was suggested that cobalamins could be used to treat a number of pathological conditions in which inflammatory oxidative stress is a clinically important component. ${ }^{26,28}$ Diminished protection against inflammatory oxidative stress in the perioperative period may be another possible mechanism responsible for delirium in patients with cobalamin deficiency. Vitamin $\mathrm{B}_{12}$ deficiency has been linked to MCI in previous studies. MCI has been associated with risk for delirium after cardiac surgery. Patients with MCI were found to have higher cortisol and IL-2 concentrations when compared to non-MCI subjects. Thus, it was suggested that cortisol and inflammatory alterations may underlie the susceptibility of these patients for delirium..$^{29,30}$

Vitamin $B_{12}$ deficiency prevalence in the United States has been reported to range from $3 \%$ to $6 \%{ }^{31}$ The reported prevalence of deficient and marginal values is much higher in developing countries. It was shown that $40 \%$ of individuals in Latin America had deficient or marginal levels of serum vitamin $\mathrm{B}_{12}{ }^{32}$ Even higher Vitamin $\mathrm{B}_{12}$ deficiency prevalence rates, up to $80 \%$, have been reported in African and Asian countries. ${ }^{33-36}$ In a previous study which was conducted in our country, the prevalence of vitamin $\mathrm{B}_{12}$ deficiency has been reported to range from $50 \%$ to $73.5 \%{ }^{7}$ The prevalence of Vitamin $\mathrm{B}_{12}$ deficiency in our study population was found to be $36.3 \%$.

Prompt treatment of $\mathrm{B}_{12}$-deficient patients is essential to avoid irreversible neurological and cognitive impairment. Improvement of delirium, depression, and psychotic symptoms after $B_{12}$ replacement therapy has been reported in previous reports in patients with $\mathrm{B}_{12}$ deficiency. ${ }^{37-39}$ The management of vitamin $\mathrm{B}_{12}$ deficiency varies between countries and between individual practices. Vitamin $B_{12}$ treatment should start preoperatively and continue postoperatively. Options available for treating a clinical vitamin $\mathrm{B}_{12}$ deficiency include high dose oral and parenteral (intramuscular or subcutaneous) preparations. Classical treatment for vitamin $\mathrm{B}_{12}$ deficiency consists of parenteral administration. ${ }^{6}$ To date, no studies have examined whether $\mathrm{B}_{12}$ replacement therapy reduces the delirium incidence in patients with $B_{12}$ deficiency undergoing cardiac surgery. Further studies are needed to examine whether vitamin $B_{12}$ replacement therapy reduces the incidence of delirium in patients with vitamin $B_{12}$ deficiency after cardiac surgery. Nevertheless, the Food and Nutrition Board recommends that even healthy older adults should take a daily vitamin $\mathrm{B}_{12}$ supplement. ${ }^{40}$

This study has several limitations. The major limitation of our study is its retrospective design. Second, postoperative cobalamin levels were not measured. Some of the potential risk factors such as renal deficiency, cognitive dysfunction, and brain chronic ischemic changes were not included in the analysis. This is another limitation of our study. Finally, this study was conducted in patients undergoing CABG surgery. Whether patients with cobalamin deficiency undergoing other types of cardiac surgery are at increased risk for delirium warrants further investigation.

\section{Conclusion}

The results of our study suggest that cobalamin deficiency may be associated with increased risk of delirium in patients undergoing $\mathrm{CABG}$. In addition, we found that preoperative cobalamin level was associated with the severity of delirium. This report highlights the importance of investigation for cobalamin deficiency in patients undergoing cardiac surgery, especially in the elderly.

\section{Disclosure}

The authors report no conflicts of interest in this work.

\section{References}

1. American Psychiatric association. Diagnostic and Statistical Manual of Mental Disorders. 5th ed (DSM 5). Washington, DC: American Psychiatric Association; 2013.

2. Simulter N, Lingehall HC, Gustafson Y, Olofsson B, Engström KG. Delirium after cardiac surgery: incidence and risk factors. Interact Cardiovasc Thorac Surg. 2013;17(5):790-796. 
3. Gottesman RF, Grega MA, Bailey MM, et al. Delirium after coronary artery bypass graft surgery and late mortality. Ann Neurol. 2010;67(3): 338-344.

4. Trabold B, Metterlein T. Postoperative delirium: risk factors, prevention, and treatment. J Cardiothorac Vasc Anesth. 2014;28(5):1352-1360.

5. Schoen J, Meyerrose J, Paarmann H, Heringlake M, Hueppe M, Berger KU. Preoperative regional cerebral oxygen saturation is a predictor of postoperative delirium in on-pump cardiac surgery patients: a prospective observational trial. Crit Care. 2011;15(5):R218.

6. Wong CW. Vitamin B12 deficiency in the elderly: is it worth screening? Hong Kong Med J. 2015;21:155-164.

7. Yildirim T, Yalcin A, Atmis V, et al. The prevalence of anemia, iron, vitamin B12, and folic acid deficiencies in community dwelling elderly in Ankara, Turkey. Arch Gerontol Geriatr. 2015;60(2):344-348.

8. Moore E, Mander A, Ames D, Carne R, Sanders K, Watters D. Cognitive impairment and vitamin B12: a review. Int Psychogeriatr. 2012; 24(4):541-556.

9. Jayaram N, Rao MG, Narasimha A, et al. Vitamin $B_{12}$ levels and psychiatric symptomatology: a case series. J Neuropsychiatry Clin Neurosci. 2013;25(2):150-152.

10. Werder SF. Cobalamin deficiency, hyperhomocysteinemia, and dementia. Neuropsychiatr Dis Treat. 2010;6:159-195.

11. Lindenbaum J, Healton EB, Savage DG, et al. Neuropsychiatric disorders caused by cobalamin deficiency in the absence of anemia or macrocytosis. N Engl J Med. 1988;318:1720-1728.

12. Hutto BR. Folate and cobalamin in psychiatric illness. Compr Psychiatry. 1997;38(6):305-314

13. Bergeron N, Dubois MJ, Dumont M, Dial S, Skrobik Y. Intensive care delirium screening checklist: evaluation of a new screening tool. Intensive Care Med. 2001;27:859-864.

14. Trzepacz P, Mittal D, Torres R, Kanary K, Norton J, Jimerson N. Validation of the Delirium Rating Scale-Revised-98: comparison with the delirium rating scale and the cognitive test for delirium. $J$ Neuropsychiatry Clin Neurosci. 2001;13(2):229-242.

15. Cinar MA, Ozmenler KN, Ozsahin A, Trzepacz PT. Reliability and validity of the Turkish translation of the Delirium Rating ScaleRevised-98. Dusunen Adam. 2014;27(3):186-193.

16. Kose G, Bolu A, Ozdemir L, Acikel C, Hatipolu S. Reliability and validity of the intensive care delirium screening checklist in Turkish Int J Nurs Knowl. Epub March 31, 2015.

17. Hshieh TT, Fong TG, Marcantonio ER, Inouye SK. Cholinergic deficiency hypothesis in delirium: a synthesis of current evidence. J Gerontol A Biol Sci Med Sci. 2008;63(7):764-772.

18. Trzepacz PT. Is there a final common neural pathway in delirium? Focus on acetylcholine and dopamine. Semin Clin Neuropsychiatry. 2000;5(2): 132-148.

19. Hindman BJ, Todd MM. Improving neurologic outcome after cardiac surgery. Anesthesiology. 1999;90:1243-1247.

20. Nakamura K, Ueno T, Yamamoto H, Iguro Y, Yamada K, Sakata R. Relationship between cerebral injury and inflammatory responses in patients undergoing cardiac surgery with cardiopulmonary bypass. Cytokine. 2005;29(3):95-104.

21. Lachner C, Steinle NI, Regenold WT. The neuropsychiatry of vitamin B12 deficiency in elderly patients. $J$ Neuropsychiatry Clin Neurosci. 2012;24:5-15.

22. Clarke R, Grimley Evans J, Schneede J, et al. Vitamin B12 and folate deficiency in later life. Age Ageing. 2004;33(1):34-41.

Neuropsychiatric Disease and Treatment

\section{Publish your work in this journal}

Neuropsychiatric Disease and Treatment is an international, peerreviewed journal of clinical therapeutics and pharmacology focusing on concise rapid reporting of clinical or pre-clinical studies on a range of neuropsychiatric and neurological disorders. This journa is indexed on PubMed Central, the 'PsycINFO' database and CAS,
23. Kruman II, Culmsee C, Chan SL, et al. Homocysteine elicits a DNA damage response in neurons that promotes apoptosis and hypersensitivity to excitotoxicity. J Neurosci. 2000;20(18):6920-6926.

24. Boldyrev AA, Johnson P. Homocysteine and its derivatives as possible modulators of neuronal and non-neuronal cell glutamate receptors in Alzheimer's disease. J Alzheimers Dis. 2007;11(2):219-228.

25. Matté C, Mackedanz V, Stefanello FM, et al. Chronic hyperhomocysteinemia alters antioxidant defenses and increases DNA damage in brain and blood of rats: protective effect of folic acid. Neurochem Int. 2009;54(1): 7-13.

26. Suarez-Moreira E, Yun J, Birch CS, Williams JH, McCaddon A, Brasch NE. Vitamin B(12) and redox homeostasis: cob(II)alamin reacts with superoxide at rates approaching superoxide dismutase (SOD). J Am Chem Soc. 2009;131(42):15078-15079.

27. Scalabrino G, Veber D, Mutti E. Experimental and clinical evidence of the role of cytokines and growth factors in the pathogenesis of acquired cobalamin-deficient leukoneuropathy. Brain Res Rev. 2008;59(1): $42-54$.

28. Birch CS, Brasch NE, McCaddon A, Williams JH. A novel role for vitamin $\mathrm{B}(12)$ : cobalamins are intracellular antioxidants in vitro. Free Radic Biol Med. 2009;47(2):184-188.

29. Kazmierski J, Banys A, Latek J, et al. Mild cognitive impairment with associated inflammatory and cortisol alterations as independent risk factor for postoperative delirium. Dement Geriatr Cogn Disord. 2014;38(1-2): $65-78$.

30. Sanford AM, Flaherty JH. Do nutrients play a role in delirium? Curr Opin Clin Nutr Metab Care. 2014;17(1):45-50.

31. Allen LH. How common is vitamin B-12 deficiency? Am J Clin Nutr. 2009;89(2):693S-696S

32. Allen LH. Folate and vitamin B12 status in the Americas. Nutr Rev 2004;62:S29-S33.

33. McLean ED, Allen LH, Neumann CG, et al. Low plasma vitamin B-12 in Kenyan school children is highly prevalent and improved by supplemental animal source foods. $J$ Nutr. 2007;13:676-682.

34. Siekmann JH, Allen LH, Bwibo NO, Demment MW, Murphy SP, Neumann CG. Kenyan school children have multiple micronutrient deficiencies, but increased plasma vitamin B-12 is the only detectable micronutrient response to meat or milk supplementation. $J$ Nutr. 2003; 133:3972S-3980S

35. Taneja S, Bhandari N, Strand TA, et al. Cobalamin and folate status in infants and young children in a low-to-middle income community in India. Am J Clin Nutr. 2007;86:1302-1309.

36. Refsum H, Yajnik CS, Gadkari M, et al. Hyperhomocysteinemia and elevated methylmalonic acid indicate a high prevalence of cobalamin deficiency in Asian Indians. Am J Clin Nutr. 2001;74:233-241.

37. Sabeen $\mathrm{S}$, Holroyd $\mathrm{S}$. Vitamin $\mathrm{B}_{12}$ and psychiatric illness. Ann Longterm Care. 2009;17:32-36.

38. Kibirige D, Wekesa C, Kaddu-Mukasa M, Waiswa M. Vitamin B12 deficiency presenting as an acute confusional state: a case report and review of literature. Afr Health Sci. 2013;13(3):850-852.

39. Kwok T, Lee J, Lam L, Woo J. Vitamin B(12) supplementation did not improve cognition but reduced delirium in demented patients with vitamin B(12) deficiency. Arch Gerontol Geriatr. 2008;46(3):273-282.

40. Institute of Medicine Food and Nutrition Board. Dietary Reference Intakes: Thiamin, Riboflavin, Niacin, Vitamin B6, Folate, Vitamin B12, Pantothenic Acid, Biotin and Choline. Washington, DC: National Academies Press; 1998.

\section{Dovepress}

and is the official journal of The International Neuropsychiatric Association (INA). The manuscript management system is completely online and includes a very quick and fair peer-review system, which is all easy to use. Visit http://www.dovepress.com/testimonials.php to read real quotes from published authors. 